\title{
A Comparative Study of the Effects of Task Repetition, Unguided Strategic Planning, and Pressured On-line Planning on the Accuracy of Upper-intermediate EFL Learners' Written Production
}

\author{
Navid Bayat \\ Islamic Azad University, South Tehran Branch, Tehran, Iran
}

Copyright $(2018$ by authors, all rights reserved. Authors agree that this article remains permanently open access under the terms of the Creative Commons Attribution License 4.0 International License

\begin{abstract}
The present study set out to explore the effects of task repetition (TR), unguided strategic planning (USP), and pressured on-line planning (POP) on the accuracy of Iranian EFL Upper-intermediate learners' written production. To achieve this, 90 EFL learners from three intact classes of an English institute were randomly assigned to three experimental groups. All participants in three groups experienced a written narrative task based on a set of six pictures as pre-test, a week prior to the 10 -session treatment, two weeks after it as post-test, and for the treatment itself as well. Participants in the first group (TR) were required to write a 150 -word narrative based on the pictures they were shown and repeat the performance a week later. In the second group (USP), participants were given 10-minute planning before performing the narrative task. Finally, students in the third group (POP) were asked to perform the task within the time limit of 17 minutes. All participants' performance was then analyzed and measured in terms of accuracy. The findings of the study revealed that repeating the task contributed in improvement in accuracy. In a similar vein, giving students the opportunity for on-line planning resulted in a similar effect on accuracy in their output, whereas no statistically significant enhancement in accuracy was achieved in strategic planning group.
\end{abstract}

Keywords Task Repetition, Unguided Strategic Planning, Pressured On-line Planning

\section{Introduction}

A methodological approach encompassing three phases of Presentation-Practice-Production (PPP) has been employed in traditional language teaching. This approach alludes to the fact that leading learners from controlled to automatic use of new language aspects is practicable through text-manipulation exercises (Ahangari \& Abdi, 2011). This approach is also known as form-based approach as that is based on the belief that we need to pay very close attention to each state of learning that learners produce the language accurately (Ahangari \& Abdi, 2011). In this approach learners are expected to produce specific grammatical forms by the end of the teaching sequence with an acceptable degree of accuracy (Willis \& Willis, 2007). Having considered the fact that due to the lack of the impressive evidence, PPP approaches have paled into insignificance, in recent years, a contrasting approach to language learning has come into existence and has gained a great deal of favor that focuses on meaning-based activities which in turn resulted in a task-based approach to foreign language teaching. Teachers provide learners with opportunities in class to use the language for real and genuine communication and the primary focus is on meaning (Willis \& Willis, 2007).

Task-Based Language Teaching (TBLT) is a realization of Communicative Language Teaching (CLT) and it has received a considerable deal of attention from second language acquisition (SLA) researchers and L2 teachers (Wang, 2008). Today, language teachers view TBLT as a fruitful approach to L2 instruction that provides them with new insights into the most effective ways in the realm of L2 teaching (Fahim \& Nourzadeh, 2011). TBLT is a response to a better understanding of language teaching process (Salimi, Alavinia, and Hosseini, 2012)."We need to distinguish between 'learning that' and 'knowing how'. In other words, we need to distinguish between knowing various grammatical rules and being able to use the rules effectively and appropriately when communicating" (Nunan, 1989; 12). In line with Robinson's (2011) contention, "TBLT places the construct of task at the center 
of curricular planning" (p. 4). Cook (2010, as cited in Robinson, 2011) noted that TBLT "sees second language learning as arising from particular tasks that students do in the classroom in a sense that it inter-conceptualizes communicative language teaching" (p. 4). A number of studies have shown that when learners have the opportunity to plan a task before they perform it, the language they produce is more fluent, accurate and complex than when no planning is possible (Ellis, 2005).

\section{Review of the Related Literature}

\section{Task Planning}

Planning for TBLT can happen in different levels, such as linguistic elements plan (e.g. choice of words or phrases), sentences plan, and structure plan (Wang, 2008). Ellis (2005) points out that all spoken and written language use, no matter how effortless and automatic it is, involves planning. Ellis's (2005) assertion categorizes task planning into two principal types which seem to have gained general acceptance. In line with his account, task planning falls into two categories: pre-task planning and within-task planning. Ellis goes on to say that the distinguishment of theses is based on when the planning takes place in that in the latter, planning takes place while learners performing the task, and in the former, it takes place prior to the performance of the task. Ellis also takes another step forward by splitting the pre-task planning into rehearsal (repetition) and strategic planning. As he proposes, in case of rehearsal, learners are provided with an opportunity to perform the task before the actual performance. In case of strategic planning, the learners are given the opportunity to consider the content they will need to encode and how to express it prior to the main performance. Strategic planning as Foster and Skehan (1996, as cited in Ellis, 2003) propose can be divided into two detailed (guided) in which students are instructed to focus on form, meaning, or both during the planning time, and undetailed (unguided) in which students receive no instruction on how to approach the task during planning time. Ellis (2005) continues to argue that within-task planning is divided into pressured and unpressured (careful) planning. In pressured planning, students undergo a time limit to perform the task, whereas, in unpressured (careful) planning, students can have a careful plan with as much time as they want to perform the task.

\section{Limited Working Memory Capacity}

One of the most frequently cited models of working memory in the literature of task planning is that of Baddeley (Ellis, 2005). This model identifies three components of working (or short-term) memory; the central executive or supervisory attentional system, phonological loop, and the visual spatial sketchpad. The central executive system governs the relationship between working memory and long-term memory, paying attention to specific long-term memory systems. This system is inherently limited in capacity; therefore, the extent to which learners are able to attend to specific system is dependent on the extent to which other systems are automatized. Ellis (2003) argues that if learners are provided with the opportunity for planning, it can reduce the burden on working memory as Ibrahim (2013) cites from Skehan (1998) that the process of SLA is controlled by one linguistic system acting in two different modes; a rule-based mode, and a ready-made exemplar mode. According to Skehan, activating the rule-based mode enables learners to develop linguistic forms. Conversely, utility of the exemplar-based mode promotes the speed of retrieving the already internalized linguistic models from memory. Skehan (1998) distinguishes three aspects of language production: fluency, accuracy, and complexity. He contends that planning in task performance reduces the learners' reliance on their ready-made exemplar system by allowing them to control their rule-based system. He goes on to assert that because of the limitations of attentional resources, learners find themselves forced to prioritize one aspect of production over the others. As a result, this 'trade-off' negatively affects the other aspects of language performance. Van Patten (1990, as cited in Salimi \& Fatollahnejad, 2012) believes that it is difficult for the L2 learners to focus on meaning and form at the same time.

The most influential and intrinsic theories in studies on oral and written task planning are Levelt's (1989) model of speech production and Kellogg's (1996) model of writing. Both models of production explicitly apply an information processing framework to an explanation of language production and the aspect in which these two models are germane to one another is that they provide a basis for taking the components of language production into account on which learners attend to while planning, and examine the effects planning strategies have on actual production (Salimi \& Fatollahnejad, 2012). Drawing on levert's (1989) model of speech production, Ellis (2003) proposes that this model identifies three stages in speech production: "(1) conceptualization, when the purpose and semantic content of a message is determined; (2) formulation, when the speaker maps grammatical and phonological features onto the preverbal message; and (3) articulation, when the phonetic plan produced by (2) is converted into actual speech" (P. 25). Kellogg's (1996,) model proposes that the process of producing written language employs three different systems: 'Formulation', 'Execution', and 'Monitoring'. Each of these systems is made up of two components. 'Formulation' consists of 'planning' and 'translating'. 'Planning' includes setting the objectives of writing, proposing related ideas, and thinking of how to present these ideas in writing. Whereas, the 'translating' is the process in which the writer transfers the planning phase 
from being just objectives and ideas into linguistic, phonological, and graphological items before 'execution'. 'Execution' involves 'programming' and 'executing'. In the 'programming' phase, the writer converts the 'translating' process into a plan for production to engage the motor system (e.g. handwriting or typing). The 'executing' phase refers to the real 'production of sentences'. 'Monitoring' comprises of 'reading' and 'editing'. 'Reading occurs only after 'executing' a sentence when writers read the texts that they have produced. The 'editing' phase can take place prior and subsequent to the executing of a sentence.

\section{Task Rehearsal (Repetition)}

Ellis (2005) defines rehearsal as task repetition; that is, learners perform "the same or slightly altered tasks-whether whole tasks, or parts of a task" (P. 43). He proposes that the repetition of a task will give the learners the opportunities to reorganize and consolidate information into a richer and more sophisticated performance. Nakakubo (2011) reports a study by Bygate (2001) involving a group of participants who watched a short cartoon video with no dialogue and told the story that the video described. Ten weeks later, Bygate asked the participants to perform exactly the same task. He concluded that repeating the task resulted in improvement in the participants' performance. In another study, Bygate $(1996$,$) asked a language learner to perform a task twice$ with a three-day interval between them. The participants of his study were required to watch a Tom \& Jerry cartoon and then to retell it. Bygate found that this kind of repetition contributed to some clear enhancement in both fluency and accuracy. Lynch \& McLean (2001, as cited in Gashan \& Almohaison, 2014) conducted an investigation which was pertinent to English for Specific Purposes (ESP) context. In their study there were fourteen English language learners performing a poster-carousal task that required them to respond repeatedly to the same or similar questions from fellow students about the poster they had prepared. They found that repetition had positive influences on both accuracy and fluency in language production. Nemeth and Kormos (2001) concluded that repeating an argumentation task enhanced the number of supports provided by the learners for their statements. Hung (2013) maintains task repetition studies have primarily focused on two issues: one centers on whether learners show better writing performance as they perform the same writing task a second time, and the other issue has to do with whether learners demonstrate better writing in a new task after participating in a repetition of task. Hung reports a study by Gass et al (1999) in which they compared these two issues together. Their study involved English speaking learners of Spanish who were required to watch video clips 3 times with 2 to 3 days interval in between and then watching a new video clip after 1 week. In the task repetition group, participants indicated improvement in overall proficiency; however, the improvement was not transferred to a new task when participants were given a new video clip for oral production. Larsen-freeman (2006, as cited in Jung, 2013) examined 5 L1 Chinese-speaking ESL learners' performance on a writing task, then oral narrative repetition tasks over a 6-month period. The findings of the study indicated that accuracy was decreased when participants repeated the task for the second time. In contrast, Ellis (1987, as cited in Jung, 2013) conducted a mixed oral-written repetition task. He concluded that task repetition gave rise to a positive effect on the accuracy. Sheppard (2006, as cited in Gashan \& Almohaison, 2014) set out to investigate the influence of repeating the oral task accompanied by feedback on accuracy and fluency. The study showed that repeating the oral task supplied by suitable feedback significantly improved the fluency and accuracy. Indrarathne (2013) reports that Birjandi and Ahangari (2008) used three types of oral tasks: a personal narrative, a story narrative, and a decision-making task in a study involving participants required to repeat the tasks. They found that task repetition increased the fluency and complexity, but the accuracy was not statistically significant. Indrarathne (2013) reports another study by Matsumura, Kawamura, and Affricano (2008) in which they compared the language production in two types of task repetition: a narrative and a decision-making task. They reported no significant enhancement in fluency, whereas the improvement in accuracy and complexity was significant.

\section{Strategic Planning}

Ellis (2005) maintains that a number of studies have explored how strategic planning impacts on task performance. Ellis (2003) explains that in case of giving students the task work plan and leaving them to decide for themselves what to plan, the results have shown that the priority was given to content over form. Ellis (2003) quotes from Foster and Skehan (1996) that when students have the opportunity to receive guidance they have the tendency to prioritize content which results in the improvement in complexity when performing the task. Following a number of studies on strategic planning, Ellis (2003) describes that findings have demonstrated that with very short period of planning, accuracy is positively benefited, whereas longer planning time is required for improving complexity. Abedifirouzjaie (2014) reports that Foster and Skehan (1999) compared the effects of focus of strategic planning on oral production. Their study revealed that the two different focuses of strategic planning (i.e. meaning-focused and form-focused) strategic planning did not contribute to different effects on the accuracy, complexity, and fluency of speech. Ellis (2003) reports a number of studies on strategic planning, for example, Crookes' (1989) study included the participants where they 
were guided to plan both the meaning and the form of their oral output. The results revealed that in both meaning and form-focused strategic planning higher complexity was reported comparing with the minimal strategic planning condition, however no accuracy increase was achieved. Later, Mehnert (1998) found the improvement in accuracy and fluency in meaning and form-focused strategic planning than the minimal strategic planning condition. Foster and Skehan (1996, as cited in Abedifirouzjaie, 2014) compared the effects of meaning/form-focused strategic planning, undetailed strategic planning, and minimal strategic planning on learners' oral performance on three different tasks: personal information exchange, oral narrative, and decision-making. They found that meaning/form-focused strategic planning resulted in higher complexity, fluency, and accuracy in the participants' oral output comparing with minimal strategic planning condition. Ortega (1999, as cited in Wang, 2008) found that L2 Spanish learners gained faster speaking speed when given time to plan strategically. Yuan and Ellis (2003) in their study concluded that strategic planning had a positive effect on fluency. Ellis (2003) continues to report more studies by mentioning an examination by Foster and Skehan (1996) where they explored the effects of more guided planning. In their study they compared the influence of detailed and undetailed planning. They concluded that in narrative task, fluency was significantly improved in guided planners than unguided planners, whereas no notable difference was reported for personal and decision-making tasks. Ellis goes on to report that Skehan and Foster (1997) found that undetailed (unguided) strategic planning resulted in greater accuracy on the personal and narrative tasks but not on the decision-making tasks. Similarly, Iwashita, Elder, and McNamara (2001) utilized a general measure of accuracy in their study. They found that in a testing situation, providing students with a 3-minute strategic planning, time had no effect on accuracy. Salimi and Fatollahnejad (2012) report a study by Ellis and Yuan (2004) that in their study they found that strategic planning contributed to greater fluency, while unpressured online planning resulted in increased accuracy.

\section{Within-Task-Planning}

Ellis (2003) reports an investigation by Hulstijn and Hulstijn (1984). The findings of their study showed that time pressure in its own right did not influence the accuracy of word order but when it was combined with a focus on form its effect was statistically significant. In another study, Ellis (1987) investigated the learners' performance on written and oral narrative tasks based on pictures. His study encompassed three tasks. He found that the learners' use of past tense forms was most accurate in task 1 and least accurate in task 3 , and in task 2 the accuracy was intermediate. He concluded that accuracy was improved when there was no time pressure. In another study cited by Ellis (2003), Yuan and Ellis (2003) made an attempt to examine the effects of pre-task and on-line planning on learners' performance on a narrative task. The findings of their study demonstrated that requiring students to perform the task in on-line planning condition resulted in both accuracy and complexity, but no improvement in fluency was observed. From the studies reported above, it can be suggested that on-line planning contributes to the enhancement of accuracy in learners' production.

Taking the literature of the past studies into consideration, it is possible to state that most empirical studies have identified significant effects of task repetition, strategic planning, and online planning on fluency, accuracy, and complexity of oral language production. Ellis (2005) postulates that there has been an increasing body of research on different aspects of L2 learners' task performance in recent years. However, it is not unwise to note that a host of this research has focused on oral performance and investigation into the effects of task repetition, strategic planning, and online planning on written production has not been paid much attention. Moreover, little research on written production in comparison with oral performance has been conducted in an international scale and there is almost little direct research on the effects of task repetition, unguided strategic planning, and pressured online planning on Iranian EFL learners' writing performance with regard to accuracy. Therefore, this study set out to bridge this gap.

\section{Research Questions and Hypotheses}

The present study is designed to address the following questions:

(1) Does task repetition have any significant effect on the accuracy of Upper-Intermediate EFL learners' written production?

(2) Does unguided strategic planning have any significant effect on the accuracy of Upper-Intermediate EFL learners' written production?

(3) Does pressured online planning have any significant effect on the accuracy of Upper-Intermediate EFL learners' written production?

(4) Do task repetition, unguided strategic planning, and pressured online planning have any differential effects on the accuracy of Upper-Intermediate EFL learners' written production?

Four null hypotheses based on the research questions are formulated and listed as follows:

H0 1) Task repetition does not have any significant effect on the accuracy of Upper-Intermediate EFL learners' written production.

H0 2) Unguided strategic planning does not have any significant influence on the accuracy of 
Upper-Intermediate EFL learners' written production.

H0 3) Pressured online planning does not have any significant effect on the accuracy of Upper-Intermediate EFL learners' written production.

HO 4) Task repetition, unguided strategic planning, and pressured online planning have equal influences on the accuracy of Upper-Intermediate EFL learners' written production.

\section{Methodology}

\section{Participants}

The participants in this study encompassed $90 \mathrm{EFL}$ students from an English institute in Tehran. Their age range was between 18 and 27 years old. For the sake of the homogeneity of the participants, prior to the treatment, the proficiency test NELT (Nelson English Language Test) was administered to 110 EFL Upper-Intermediate students. From this pool 90 students who scored high in comparison with others participated in the study. At the same time the data were collected, most of these learners had been learning English as a foreign language in language institute in Tehran for 5 years. None of them had ever been to an English-speaking country and they had had little opportunity to use English for communicative purposes outside the classroom. All participants had been assigned to the Upper-Intermediate level of proficiency after a placement test and interview already conducted by the institute. All students met 3 times a week for one and a half hour for a total number of 16 sessions. The participants can be considered to constitute a fairly homogeneous group of students in terms of their learning history and English proficiency. These 90 participants were randomly divided into three groups. These three groups were labeled as the task repetition group (TR), unguided strategic planning group (USP), and pressured online planning group (POP). They were not told the precise purpose of the research and they were assured that the information collected would not be used toward their course grade.

\section{Design}

In this research, quantitative research paradigm was employed. The research was primarily quasi-experimental in design as it did not involve any control groups and explanatory in purpose.

\section{Instrumentations}

In order to conduct this study, the researcher used the following instruments:

1. Nelson (test of English homogeneity): The test was taken from Flower and Norman's (1976, as cited in
Azizzadeh and Dobakhti, 2015) book, and consisted of 50 multiple-choice items, including reading, grammar, vocabulary, and pronunciation, to each of which one point was assigned. The participants had 40 minutes to answer it.

2. Materials for the narrative tasks: Drawing on many of the previous task planning studies (Crookes, 1989; Elder \& Iwashita, 2005; Foster \& Skehan, 1996; Gilabert, 2007; Kawauchi, 2005a, 2005b; Mochizuki \& Ortega, 1999; Park, 2006; Skehan \& Foster, 1997; Tavakoli \& Skehan, 2005; Yuan \& Ellis, 2003, as cited in Nakakubo, 2011), this study used written narrative tasks with the sets of pictures to examine L2 learners' written production.

3. Pre-test and post-test narrative writing tasks: Two narrative writing tasks consisting of two sets of wordless picture stories which were chosen from Julich and Chabot's (2006) book were used as the prompts to elicit written narratives of the participants during the pre-test and post-test phases. These wordless picture stories have been successfully used in linguistic research to elicit both EFL/ESL oral and written narratives (e.g. Ellis, 2003).

\section{Procedures}

Obtaining the verbal permission of the manager of the language institute, three intact classes, each including 30 Upper-Intermediate EFL learners were selected. All three groups were taught by their own instructors in the institute. However, the instructors were trained about two hours by the researcher for clarifying the procedure of the study and about what they were expected to do during the study. In this study, planning is operationalized at three levels: (1) task repetition, (2) unguided strategic planning, and (3) pressured on-line planning. A week prior to commencing the treatment sessions, all three groups experienced pre-test to appraise their production in the narrative writing skills with regard to accuracy. Two weeks (Mackey \& Gass, 2005) after the ten sessions of treatment, a post-test encompassing the same procedure pre-test was administered. The purpose of administering the post-test was to determine to what extent the participants' writing accuracy was improved due to the treatment.

In task repetition group (TR), participants were shown a set of six pictures from Julich and Chabot's (2006) book that told them a story. They were required to write a 150-word narrative story drawing on Ellis and Yuan's (Ellis, 2005) study based on those pictures. They were given as much time as they needed to complete that task. After a two-week interval, capitalizing on (Bamanger, 2014; Gashan \& Almohaison, 2014), they were required to perform the same task. However, at the outset of the treatment, students were not told that they were supposed to repeat the same task in upcoming weeks. 
In unguided strategic planning group (USP), participants were first shown a set of six pictures that told them a story. Then, they were given a ten-minute preparation time (Crookes, 1989; Foster, 1996; Kawauchi, 2005a, 2005b; Mehnert, 1998; Ortega, 1999; Skehan \& Foster, 1997; 2005; Wendel, 1997; Yuan \& Ellis, 2003, as cited in Nakakubo, 2011) to plan for the performance. Since the category of the planning condition was unguided, they were free to choose any strategies they wanted such as writing a composition, reading a story, practice etc., in order to perform the task. After the ten minutes of preparation time, their notes were collected by their teacher and they asked to write a 200-word narrative writing based on the pictures they were shown. They were also given as much time as they wanted to complete the task.

In pressured on-line planning group (POP), participants were asked to perform the written narratives immediately after looking at the pictures without any preparation time. Moreover, they were told to perform the task within the framework of 17 minutes (Ellis, 2005). So, they had to write their narratives under time pressure. They had to both plan and write during this time limit.

\section{Measurement}

To evaluate accuracy of L2 written production, the percentage of error-free clauses was employed. Nakakubo (2011) describes that the percentage of error-free clauses has been most commonly used in previous planning studies (Ellis \& Yuan, 2005; Elder \& Iwashita, 2005; Foster \& Skehan, 1996; Mehnert, 1998; Sangarun, 2005; Skehan \& Foster, 1997, 2005; Tajima, 2003; Tavakoli \& Skehan, 2005; Yuan \& Ellis, 2003). Errors could be syntactic, morphological, or lexical, including inappropriate use and erroneous omission of words and grammatical elements and incorrect word order. For accuracy, all of the errors in the narratives were coded. Error-free clauses were those that contained no error. The percentage of error-free clauses for each narrative story was calculated by dividing the number of error-free clauses by the total number of clauses in the narrative.

Number of error-free clauses $\div$ Total number of clauses in the narratives X 100

\section{Data Analysis and Results}

\section{Proficiency Test Results}

In order to ensure that the students in the three groups are in the same level of English language proficiency, one-way ANOVA was used. Before discussing the results of inferential analysis, the descriptive statistics of participants' Nelson scores for the task repetition, unguided strategic, and pressured online planning groups are given in
Table 4.1. As can be seen in Table 4.1, the means of Nelson scores for task repetition $(\bar{x}=38.20, S D=3.74)$ unguided strategic $(\bar{x}=37.03, S D=4.23)$, and pressured online planning $(\bar{x}=38.60, S D=4.39)$ groups are not very far from each other. In addition, Table 4.1 shows that the ratios of skewness and kurtosis of the Nelson scores over their respective standard errors are not beyond the ranges of $+/$ 1.96 , and therefore are normally distributed.

Table 4.1. Descriptive Statistics for Nelson Proficiency Test Scores in the Groups

\begin{tabular}{|c|c|c|c|c|c|}
\hline Group & $N$ & Mean & $S D$ & Skewness & Kurtosis \\
\hline Task repetition & 30 & 38.20 & 3.745 & -.007 & -.852 \\
\hline Unguided strategic & 30 & 37.03 & 4.230 & -.154 & -.927 \\
\hline Pressured online & 30 & 38.60 & 4.399 & -.241 & -1.036 \\
\hline
\end{tabular}

The results of Levene's test (Table 4.2) indicate that the assumption of homogeneity of variance is not violated since the Sig. associated with Levene's test (.55) is more than .05 .

Table 4.2. Levene's Test of Equality of Error Variances (Pre-test)

\begin{tabular}{|c|c|c|c|}
\hline Levene Statistic & $d f 1$ & $d f 2$ & Sig. \\
\hline .596 & 2 & 87 & .553 \\
\hline
\end{tabular}

Table 4.3 below represents the results of ANOVA that was used to compare the homogeneity test measures for the three groups. We used ANOVA as a parametric analysis since four assumptions of using parametric analysis (i.e., interval data, independence of subjects, normality and homogeneity of variances) were met if not, we were forced to use non-parametric analysis of Kruskal Wallis test. Based on Table 4.3, ANOVA results indicate that there are no statistically significant differences in Nelson scores among the three groups at the $p<.05$ level, $F(2,87)=1.16$, $p=.31, p>.05$, in which our $F$-value is below the $F$-critical (3.09). Then it is concluded that the students in the three groups are homogeneous regarding English language proficiency.

Table 4.3. ANOVA for Comparing the means for the Three Groups

\begin{tabular}{|c|c|c|c|c|c|}
\hline & $\begin{array}{c}\text { Sum of } \\
\text { Squares }\end{array}$ & $d f$ & $\begin{array}{c}\text { Mean } \\
\text { Square }\end{array}$ & $F$ & Sig. \\
\hline $\begin{array}{c}\text { Between } \\
\text { Groups }\end{array}$ & 39.756 & 2 & 19.878 & 1.163 & .317 \\
\hline $\begin{array}{c}\text { Within } \\
\text { Groups }\end{array}$ & 1486.967 & 87 & 17.092 & & \\
\hline Total & 1526.722 & 89 & & & \\
\hline
\end{tabular}

Figure 4.1 below is a Box Plot that graphically displays the results. As it can be seen clearly in Figure 4.1, the students in the task repetition, unguided strategic, and pressured online planning groups have performed almost the same considering English language proficiency. 


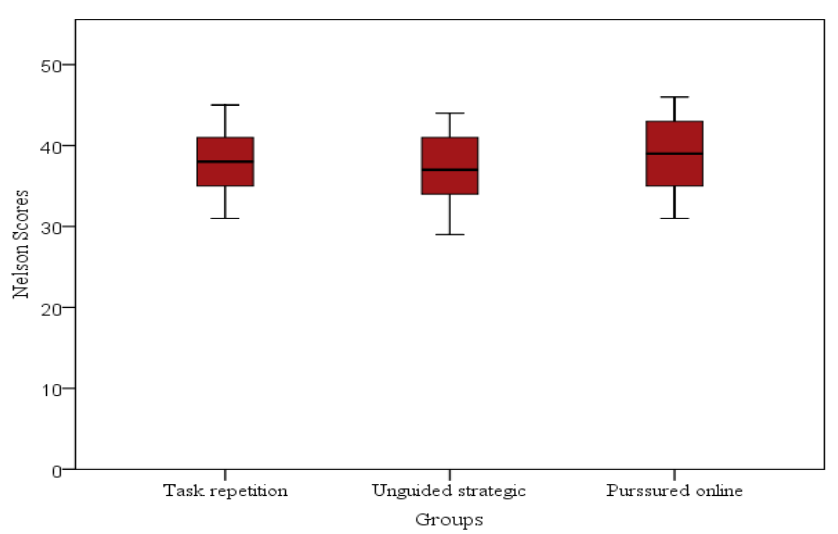

Figure 4.1. Nelson means for the three groups (pre-test)

\section{Analysis of the Research Questions 1, 2, \& 3}

In order to answer first, second, and third research questions, paired sample $t$-test was used. Before discussing the results of this analysis, the related descriptive statistics were computed (Table 4.4). Table 4.4 indicates that the mean score of clause accuracy enhances considerably from pre-test to post-test in both task repetition and pressured online planning groups, but not in the unguided strategic group. Besides, as Table 4.4 shows, the normality assumption of all sets of scores for conducting parametric analysis are not violated as the ratios of skewness and kurtosis over their respective standard errors are not beyond the expected ranges $(+/-1.96)$.

Table 4.4. Descriptive Statistics for Clause Accuracy Measures in the Groups

\begin{tabular}{|c|c|c|c|c|c|c|c|c|}
\hline Variable & Pair & Group & Time & Mean & $\mathrm{N}$ & $\mathrm{SD}$ & Skewness & Kurtosis \\
\hline \multirow{6}{*}{ Clause } & \multirow{2}{*}{ Pair 1} & \multirow{2}{*}{ Task } & Post-test & 85.17 & 30 & 5.855 & -.159 & -.910 \\
\hline & & & Pre-test & 77.73 & 30 & 4.354 & -.059 & -.578 \\
\hline & \multirow{2}{*}{ Pair 2} & \multirow{2}{*}{ Unguided } & Post-test & 77.10 & 30 & 5.720 & -.227 & -.852 \\
\hline & & & Pre-test & 76.63 & 30 & 5.549 & -.196 & -.705 \\
\hline & \multirow{2}{*}{ Pair 3} & \multirow{2}{*}{ Pressured } & Post-test & 81.20 & 30 & 6.105 & .208 & -.661 \\
\hline & & & Pre-test & 76.33 & 30 & 6.025 & .195 & -1.235 \\
\hline
\end{tabular}

Table 4.5 represents the results of paired samples $t$-test was applied to compare the means of verb and clause accuracy scores across the groups.

Table 4.5. Paired Samples T-test for Clause Accuracy Measures in the Groups

\begin{tabular}{|c|c|c|c|c|c|c|}
\hline Variable & Group & Mean & $S D$ & $t$ & $d f$ & Sig. (2-tailed) \\
\hline \multirow{3}{*}{ Clause } & Task & 7.433 & 5.716 & 7.123 & 29 & .000 \\
\cline { 2 - 8 } & Unguided & .467 & 2.609 & .980 & 29 & .335 \\
\cline { 2 - 8 } & Pressured & 4.867 & 5.257 & 5.070 & 29 & .000 \\
\hline
\end{tabular}

Based on Table 4.5 above, paired-samples $t$-test found a statistically significant increase in clause accuracy scores, $t$ $(29)=7.12, p<.01$ (two-tailed) from pre-test to post-test in the task repetition group. Accordingly the first null hypothesis that states "Task repetition does not have any significant effect on the accuracy of upper-intermediate EFL learners' written production" is rejected. So, as Figure 4.2 displays, it can be claimed that task repetition develops the accuracy of upper-intermediate EFL learners' written production.

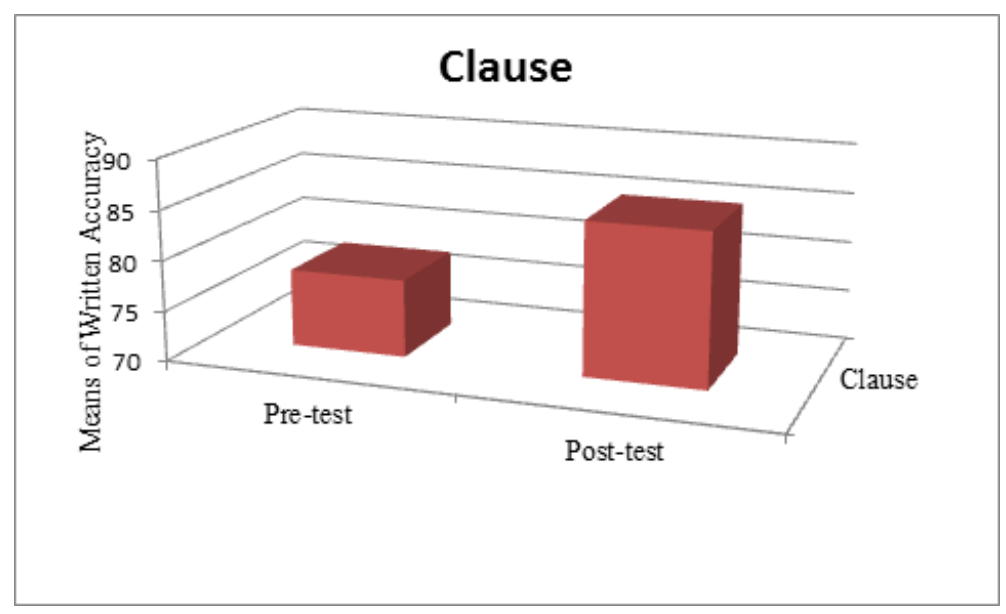

Figure 4.2. Clause accuracy means in the task repetition group (pre-test \& Post-test) 
Additionally, paired-samples $t$-test results (Table 4.5) indicated that there was no statistically significant increase in clause accuracy scores , $t(29)=.98, p>.05$ (two-tailed) from pre-test to post-test in the unguided strategic group. As a result the second null hypothesis that says, "Unguided strategic planning does not have any significant effect on the accuracy of upper-intermediate EFL learners' written production" is confirmed. Therefore, as Figure 4.3 demonstrates, it can be declared that unguided strategic planning does not affect the accuracy of upper-intermediate EFL learners' written production.

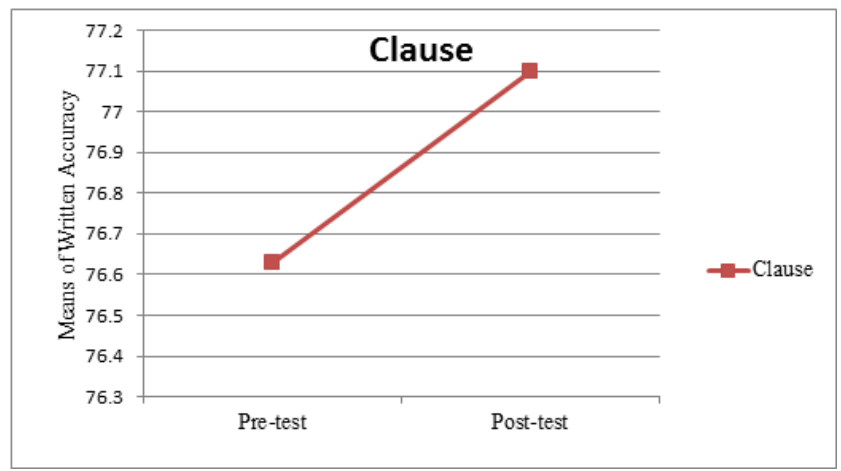

Figure 4.3. Clause accuracy means in the unguided strategic planning group (pre-test \& Post-test)

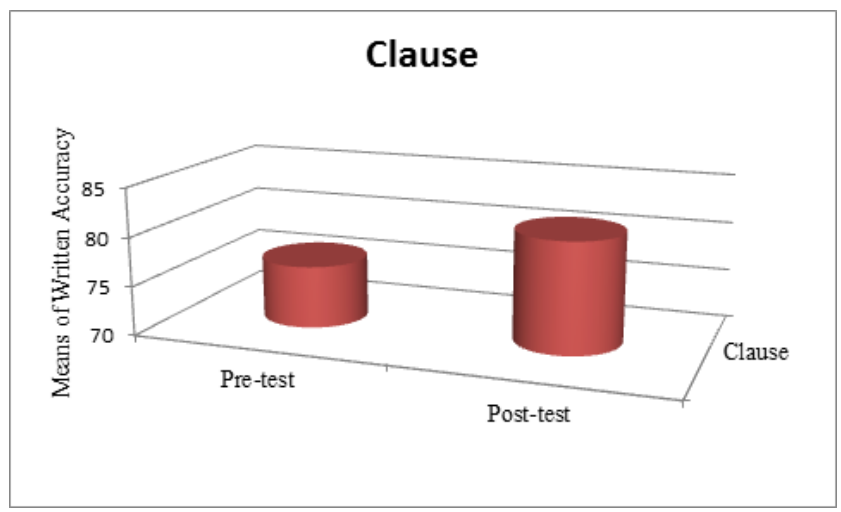

Figure 4.4. Clause accuracy means in the pressured online planning group (pre-test \& Post-test)

As Table 4.5 shows, paired-samples $t$-test detected a statistically significant increase in clause accuracy scores, $t(29)=5.07, p<.01$ (two-tailed) from pre-test to post-test in the pressured online planning group. Consequently the third null hypothesis that mentions, "Pressured online planning does not have any significant effect on the accuracy of upper-intermediate EFL learners' written production" is rejected. Thus, as Figure 4.4 illustrates, and it can be claimed that pressured online planning improves the accuracy of upper-intermediate EFL learners' written production.

\section{Analysis of Research Question 4}

The fourth research question of this study sought to find out whether task repetition, unguided strategic planning, and pressured online planning have any differential effects on the accuracy of upper-intermediate EFL learners' written production. A one-way multivariate ANOVA was used to answer this research question.

Table 4.6 shows that the probabilities associated with the Levene's F-values are greater than .05 for all measures of clause accuracy on both pre-test and post-test. As a result the assumption of homogeneity of variances is met.

Table 4.6. Levene's Test of Equality of Error Variances (Pre-test)

\begin{tabular}{|c|c|c|c|c|c|}
\hline Variable & & $F$ & $d f 1$ & $d f 2$ & Sig. \\
\hline \multirow{2}{*}{ Clause } & Pre-test & 2.504 & 2 & 87 & .088 \\
\cline { 2 - 6 } & Post-test & .001 & 2 & 87 & .999 \\
\hline
\end{tabular}

In order to compare the three groups' measures of verb and clause accuracy on the pre-test and post-test of writing, one-way multivariate ANOVA was used; the results of which are laid out in Table 4.7.

As the results in Table 4.7 indicates, multivariate tests showed that there was not any statistically significant difference, Wilks' Lambda $=.934, F(4,172)=1.49, p>.05$, between the three groups on the overall dependent variables ( e.i. clause) on the pre-test, but on the post-test there was statistically significant difference, Wilks' Lambda $=.674, F(4,172)=9.37, p<.01$, Partial $\eta 2=.17$ indicating a relatively moderate effect size based on Cohen's guidelines (1988, pp. 284-7) between the three groups on the overall dependent variables (e.i. clause). Hence we could reject the fourth null hypothesis as "Task repetition, unguided strategic planning, and pressured online planning do not have equal influences on the accuracy of upper-intermediate EFL learners' written production". In fact it was uncovered that task repetition, unguided strategic planning, and pressured online planning have different influences on the accuracy of upper-intermediate EFL learners' written production.

Table 4.7. Multivariate Tests (One-way MANOVA)

\begin{tabular}{|c|c|c|c|c|c|c|c|c|}
\hline & \multicolumn{2}{|c|}{ Effect } & Value & F & Hypothesis df & Error df & Sig. & Partial Eta Squared \\
\hline \multirow{3}{*}{ Pre-test } & Intercept & Wilks' Lambda & .005 & 9171.781 & 2.000 & 86.000 & .000 & .995 \\
\cline { 2 - 10 } & Group & Wilks' Lambda & .934 & 1.495 & 4.000 & 172.000 & .206 & .034 \\
\hline \multirow{2}{*}{ Post-test } & Intercept & Wilks' Lambda & .004 & 11805.50 & 2.000 & 86.000 & .000 & .996 \\
\cline { 2 - 10 } & Group & Wilks' Lambda & .674 & 9.376 & 4.000 & 172.000 & .000 & .179 \\
\hline
\end{tabular}


Table 4.8. Post Hoc Pair Wise Comparisons

\begin{tabular}{|c|c|c|c|c|c|}
\hline \multirow{2}{*}{ Dependent Variable } & (I) Group & (J) Group & Mean Difference (I-J) & Std. Error & Sig. $^{{ }^{a}}$ \\
\hline \multirow{3}{*}{ Clause (Post-test) } & Task & Unguided & $8.067^{*}$ & 1.522 & .000 \\
\cline { 2 - 7 } & Task & Pressured & $3.967^{*}$ & 1.522 & .011 \\
\cline { 2 - 7 } & Unguided & Pressured & $-4.100^{*}$ & 1.522 & .008 \\
\hline
\end{tabular}

For further analysis locating the exact differences, post hoc pair wise comparisons were made (Table 4.8)

ANOVA (Table 4.8) detected a significant difference in clause accuracy measures for all possible pairs of task repetition, unguided strategic planning, and pressured online planning groups, $p<.05$ on the post-test of writing. That means, as Figure 4.6 illustrates, the students in the task repetition group $(M=85.17, S D=5.85)$ have had the best performance on applying accurate clauses on the post-test of writing, followed by the pressured $(M=81.20$, $S D=6.10)$, and then the unguided group $(M=77.10, S D=$ 5.72).

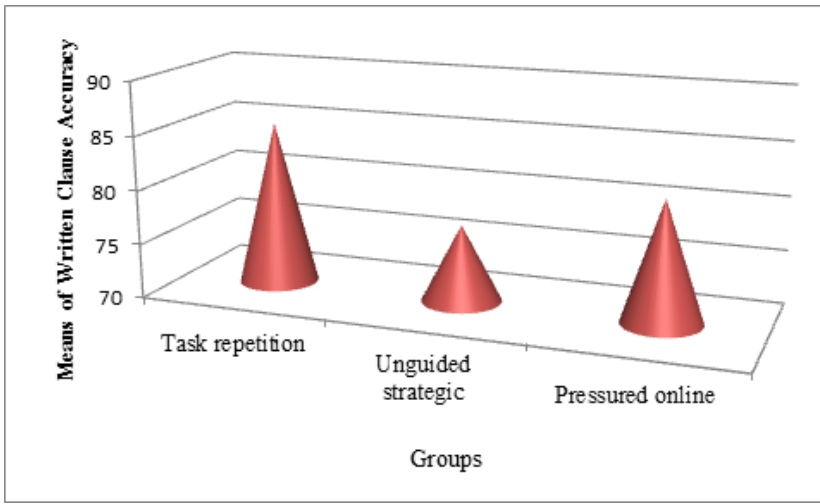

Figure 4.6. Written clause accuracy means on the post-test

\section{Discussion}

This study was primarily aimed at examining the effects of task repetition, unguided strategic planning, and pressured online planning conditions on accuracy of EFL learners' written production. In this section, the researcher summarizes the findings of the study and discusses the findings in relation to other studies.

Using a range of measures, the researcher found some evidence that repeating the task, and online planning resulted in improvement in learners' written performance. With respect to the first research question posed, examining the effects of task repetition on accuracy, it was found that the participants in task repetition group, in comparison with the results of their pre-test, in their post-test the outperformed in the number of error-free clauses produced. In this regard, this finding is consistent with the findings that Kawamura and Affricano (2008), Hawkes (2011), Lynch and Mclean (2000), Larsen-freeman (2006), Ellis (1987), Bygate (1996), Sheppard (2006), Birjandi and Ahangori (2008), Ahmadian and Tavakoli (2011), Zohrabi and Abbasvand (2014), obtained. In these studies it is concluded that giving learners the opportunity to repeat the task contributes to the enhancement of the accuracy of their production. The findings are supported by information processing theory that human beings possess limited capacity in working memory which does not allow the learner to attend to all aspects of the language at the time of task performance. However, the findings of the present study are in contrast with the studies that Bygate (2001), Gass et al (1999), Crookes (1989), Tavakoli and Skehan (2005), and Taguchi (2008) conducted in which they reported no significant positive effect of repetition on accuracy.

In terms of the second research question the results of the present study indicate that pre-task planning which is operationalized into unguided strategic planning condition has no statistically significant effect on accuracy of the participants' written production. The results of the study are also supported by Skehan's (1998, as cited in Ahangari and Abdi, 2011) cognitive approach which states that language performers vary in the extent to which they prioritize accuracy, complexity, and fluency with some tasks predisposing them to attend to complexity, and others on accuracy. The findings of this study are in line with the findings of Menhert (1998), Foster and Skehan (1996), Wendel (1997), Crookes (1989), Foster and Skehan (1999), obtained. All the studies that are mentioned have demonstrated that providing learners with the opportunity to plan before commencing the main performance would not result in any significant improvement in the accuracy of their output. In this study it was found that providing learners with the opportunity to plan the written narrative task performance, they give priority to being less accurate. However, the results of this study do not lend support to the findings of Foster and Skehan (1996), Sanguran (2005), Wigglesworth (1997), and Kawauchi (2005) in which they claimed that positive influence was observed in the learners' accuracy after being given the strategic planning time.

With regard to the third research question, it was revealed that pressured online planning condition positively influenced the accuracy of the learners' production. The results are in agreement with those of Hulstjin and Hulstjin (1984), Ellis (1987), and Wigglesworth (1997), and Yuan and Ellis (2003). These studies suggest that the time learners are given for online planning improves the accuracy of their production. However, the present study's findings may run against Skehan's (1998) dual-mode system proposal. Skehan states 
that rule-based system is likely to be parsimoniously organized, in that, rules are compactly structured (Ghavamnia, Tavakoli, and Steki, 2012). Therefore, when learners are given as much time as needed and are not pressured for time they are likely to draw on their rule-based system, which in turn, results in the improvement in the level of accuracy. The results of this study demonstrated that creating a test-like situation for learners to perform the task by being required to complete the task under the time pressure would give rise to the positive influence in the accuracy of their written production as the same as it was concluded in afore-mentioned studies.

\section{Conclusions}

Task is the key term in TBLT. It is necessary to make a clear understanding of it before examining into specific areas in TBLT. Although there are many different perceptions of task, some accords and agreements are achieved. Apparently, in TBLT, planning plays a very crucial and important role, and students' language performances are measured from the aspects of complexity, accuracy, and fluency. The influence of planning on students' language performances is thoroughly examined in the literature. Task repetition has positive influence on students' language production. However, the influence of strategic planning on accuracy is not very clear. Unpressured within-task planning positively influences students' accuracy of performance. Pressured online planning condition might have positive influence on students' language performance as the results of the present study suggest but there are not enough studies to prove it.

This has important implications for writing pedagogy. Depending on the purpose of writing tasks teachers assign EFL learners, different aspects of the writing performance can be emphasized by altering the type of planning conditions.

\section{REFERENCES}

[1] Abedifirouzjaie, J, (2014). The effect of different strategic planning foci on the accuracy of writing task performance. Texas Paper in Foreign Language Education, 16(1), 45-48.

[2] Ahangari, S., Abdi, M. (2011). The effect of pre-task planning on the accuracy and complexity of Iranian EFL learners' oral performance. Procedia - Social and Behavioral Sciences, 29, 1950-1959.

[3] Azizzadeh, L., \& Dobakhti, L. (2015). The effect of task repetition on complexity and accuracy of Iranian high-intermediate EFL learners' narrative writing performance. International Journal of Applied Linguistics and English Literature, 4 (2), 17-19. doi: 10.7575/aial.ijalel.7.4n.2-17.
[4] Bygate, M. (1996). Effect of task repetition: appraising the development of second language learners. In J. Willis and D. Willis (Eds.). Challenge and change in language teaching (pp. 136-146). Oxford: Heinemann.

[5] Ellis, R. (2003). Task-based language learning and teaching. Shanghai. China: Oxford University Press.

[6] Ellis, R. (2005). Planning and task performance in a second language. Amsterdam: John Benjamins.

[7] Gashan, A., \& Almohaisen, F. (2014). The effect of task repetition on fluency and accuracy of EFL Saudi learners' oral performance. Advances in Language and Literary Studies, 5(3), 378. doi: 10.7575/aiac.alls.v.5n.3p.36

[8] Ibrahim, T. (2013). The effects of pre and within-task planning on L2 written accuracy: A longitudinal study in the context of ADEC's English continuous rich task (ECART) (unpublished Master's dissertation). The British University, Dubai.

[9] Indrarathne, B. (2013). Effects of task repetition on written language production in task based language teaching. Papers from the Lancaster University Postgraduate Conference in Linguistics \& Language Teaching, 42-46.

[10] Julich, J., \& Chabot, J. (2006). Sequences. Picture Stories for ESL. Saint Catharines, Canada: FB Production.

[11] Jung, S. (2013). The effect of task repetition on corrective feedback in L2 writing. MSU Working Papers in SLS, 4, 26-29.

[12] Kellog, R. (1996). A model of working memory in writing. In C. Levy and S. Ransdell (Eds.). The science of writing (pp. 57-71). Mahwah, NJ: Erlbaum.

[13] Mackey, A \& Gass, S. (2005). Second Language Research. Methodology and Design._Mahwah, NJ: Lawrence Erlbaum Associates.

[14] Mojavezi, A. (2013). The relationship between task repetition and language proficiency. Applied Research on English Language, 3(1), 30-31.

[15] Nakakubo, T. (2011). The effects of planning on second language oral performance in Japanese: Process and production (Doctoral dissertation, University of Iowa, Japan). Retrieved from http://ir.lliowa.edu/etd/1038

[16] Nermeth, N \& Kormos, J. (2001). Pragmatic aspects of task-performance: The case of argumentation. Language Teaching Research, 5, 213-240.

[17] Nunan, D. (1989). Designing tasks for the communicative classroom. Cambridge, UK: Cambridge University Press.

[18] Robinson, P. (2011). Task-based language learning. West Sussex, UK: Language Learning Research Club, University of Michigan.

[19] Salimi, A., Alavinia, P., \& Hosseini, P. (2012). The effect of strategic planning time and task complexity on L2 written accuracy. Theory and Practice in Language Studies, 2 (11), 2308-2315. doi: 10.4304/tpls.2.11.

[20] Salimi, A., \& Fatollahnejad, S. (2012). The effect of strategic planning and topic familiarity on Iranian intermediate EFL learners' writing performance in TBLT. Theory and Practice in Language Studies, 2 (11), 2308-2315. 
doi: $10.4304 /$ tpls.2.11.

[21] Wang, Y. (2008). Influence of planning on students' language performance in task-based language teaching.
English Language Teaching, 1(1), 83-85.

[22] Willis, D., \& Willis, J. (2007). Doing task-based teaching. Shanghai, China: Oxford University Press. 